\title{
Research on Evaluation of Regional Logistics Capability under Big Data Background
}

\author{
Wenfeng Zhao ${ }^{1, *}$ and Jiapeng Zhang ${ }^{1}$ \\ ${ }^{1}$ Management Engineering Department, Zhengzhou University, Zhengzhou, China \\ Corresponding Email: 15136836918@163.com
}

\begin{abstract}
Over the past few years, the emerging information technology has greatly promoted the development of e-commerce, and then the level of the logistics industry's ability to put forward higher requirements. At this stage, the development of regional logistics is not balanced, the problems of each region are not the same. In this paper, the regional logistics capability evaluation system is established by analytic hierarchy process (AHP). The paper analyzes and evaluates the regional logistics development in six typical provinces, and puts forward suggestions to promote the regional logistics capability, so as to promote the sound development of regional logistics.
\end{abstract}

\section{Introduction}

Now, a variety of new information technology emerging in the mobile computing, Internet of Things, cloud computing and other technical support, people in the information exchange and commodity trading is more convenient and efficient.

In the age of information explosion, the amount of data has been increasing rapidly. The redundancy and complexity of data are becoming more and more obvious. Traditional data mining methods and technologies are unable to cope with the large-scale data rapidly emerging in the field of technology. Level data processing and application, thus losing the auxiliary decision-making based on data analysis programs and capabilities [1].Large data comprehensive information and network based on the new business model and production model, is to redefine the social management and national strategic decision-making, business management decision-making, organizational business processes, personal decision-making process and way, the extensive use of large data will bring human society The Third Industrial Revolution. "Cannot be within a certain period of time using conventional software tools to capture, manage, process data collection" This sentence is Wikipedia on the definition of large data, the concept of large data, the industry does not have a unified view. The term "big data" first appeared in the 1980 's, but the big data has only been used as another description in the definition of data mining technology. It is confined to the computer science disciplines and has not formed prominent research results with influence and representative significance. And research programs [2]. When large data is seen as a resource, it cannot ignore the access to such resources, processing problems, application issues, each of which is an important management problem. At present, people are aware of large data perspective there is a difference, the main reason for this difference is that people analyze the background of large data and application of large data for different purposes [3].In recent years, China's rapid economic growth, regional logistics in the economy under the impetus of the rapid development, therefore, the development of regional logistics from the actual demand, how to effectively grasp the "big data" environment, opportunities and challenges, Data "to the traditional logistics management work brought about by the thinking system to the technical methods of the great changes, to seek a more scientific and effective way to enhance the level of logistics capacity in the region. ${ }^{[4]}$ It is not only the foothold of this paper but also the practical problem that this paper is expected to solve in order to realize the decision-making innovation of regional logistics management in our country.

\section{Basic concepts of regional logistics capability}

Regional logistics in the academic and national standards so far has not yet formed a unified concept, which Dong Qianli that regional logistics and logistics control and supervision of the relevant operating system Haifeng emphasizes the regional logistics is the transport, Loading and unloading, handling, circulation processing, distribution and information processing and other basic activities of the logistics of organic synthesis. 
The regional logistics described in this article is to maximize the integration of logistics resources, save logistics costs and improve economic efficiency, to provide efficient and rational organization and management of regional economic development, in the context of environmental, political, economic, military and other regional background. Technical support, so as to boost regional economic sustainable and rapid development of a system of logistics concepts.

\section{Establishment of evaluation index system of regional logistics capability}

Based on the statistical methods of the China Statistical Yearbook and considering the availability of data, this paper proposes four suggestions on regional logistics service capability B1, regional logistics talent contribution capacity B2, regional logistics fixed assets support capability B3 and regional logistics economic competitiveness B4. Logistics capacity of $\mathrm{C} 1, \mathrm{C} 2$, posts and telecommunications $\mathrm{C} 3$, the number of employees in the logistics industry $\mathrm{C} 4$, the number of employees in the logistics industry accounted for the tertiary industry, the number of employees in the logistics industry accounted for the first three indicators, The proportion of the number of employees $\mathrm{C} 5$, the logistics industry, investment in fixed assets C6, the fixed assets investment in the logistics industry, the proportion of total investment in fixed assets $\mathrm{C} 7$, at the end of the road mileage $\mathrm{C} 8, \mathrm{C} 9$ logistics industry, wholesale and retail trade added value $\mathrm{C} 10$, The proportion of the output value of the total output value of tertiary industry $\mathrm{C} 11$, the proportion of the total output value of logistics industry GDP.

\section{Analytic hierarchy process (AHP)}

\subsection{Analytic hierarchy process}

The analytic hierarchy process (AHP) is used to judge the importance degree of the two indexes by decomposing the complex problem into several layers and several factors.

The judgment matrix is established by calculating the maximum eigenvalue and the corresponding eigenvector of the judgment matrix. The weight of the importance of the factors at all levels, providing the basis for the choice of the best option [4].

\subsection{The basic steps of AHP}

\subsubsection{Identify the problem}

By clarifying the scope of the problem, the specific requirements put forward, the elements involved and the relationship between the elements, you can clear what to solve the problem, the need for intelligence information has to meet the demand.

\subsubsection{Establish hierarchical hierarchical structure}

Hierarchical structure can be divided into three levels, the first level is the target layer, the second layer is the standard layer, the third-level program layer, the different levels of the relationship between the elements with the connection.

\subsubsection{Establish the judgment matrix}

The evaluation scale of the judgment matrix is shown in Table 1:

Table 1. 1-9 scale table.

\begin{tabular}{|c|l|}
\hline Scale & \multicolumn{1}{c|}{ Meaning } \\
\hline 1 & means that the two factors have the same importance \\
\hline 3 & one factor is slightly more important than the other \\
\hline 5 & one factor is significantly more important than the other \\
\hline 7 & one factor is more important than the other \\
\hline
\end{tabular}




\begin{tabular}{|c|l|}
\hline 9 & one factor is more important than the other \\
\hline $2,4,6,8$ & Intermediate value of the above adjacency judgment \\
\hline reciprocal & Judgment bij of the reciprocal factor $\mathrm{i}$ is compared with $\mathrm{j}$, and $\mathrm{bij}=1 / \mathrm{bij}$ \\
\hline
\end{tabular}

\subsubsection{Hierarchical single sorting and hierarchical total sorting}

(1)The relative importance of the calculation. Then the maximum eigenvalue is obtained for the judgment matrix, and then the corresponding eigenvector $\mathrm{W}$ is obtained.

The component of $\mathrm{W}\left(\mathrm{W}_{1}, \mathrm{~W}_{2}, \ldots \mathrm{W}_{\mathrm{n}}\right)$ is the weight coefficient.

(2)Consistency check. $\lambda_{\max }=\mathrm{n}$, The random consistency ratio C.R. $=$ is used, C.R. $=\frac{\text { C.I. }}{R . I .}$.and the consistency test is considered to be acceptable when C.R. $\leqq 0.10$

The standard values of R.I. are shown in Table 2.

Table2. Average random consistency index.

\begin{tabular}{|c|c|}
\hline Order & R.I. \\
\hline 3 & 0.52 \\
\hline 4 & 0.89 \\
\hline 5 & 1.12 \\
\hline 6 & 1.26 \\
\hline 7 & 1.36 \\
\hline 8 & 1.41 \\
\hline 9 & 1.46 \\
\hline 10 & 1.49 \\
\hline 11 & 1.52 \\
\hline 12 & 1.54 \\
\hline
\end{tabular}

\subsubsection{Hierarchical total sorting}

The total ranking of the hierarchy is calculated as shown in table3.

Table3. Hierarchical ranking calculation.

\begin{tabular}{|c|cccc|c|}
\hline \multirow{2}{*}{$\mathrm{A}$} & $A_{1}$ & $A_{2}$ & $\cdots$ & $A_{m}$ & \multirow{2}{*}{ B Hierarchical total sorting } \\
\cline { 2 - 5 } & $a_{1}$ & $a_{2}$ & $\cdots$ & $a_{m}$ & \\
\hline $\mathrm{B}_{1}$ & $b_{1}{ }^{1}$ & $b_{1}{ }^{2}$ & $\cdots$ & $b_{1}{ }^{m}$ & $\sum_{j=1}^{m} a_{j} b_{1}^{j}$ \\
$B_{2}$ & $b_{2}{ }^{1}$ & $b_{2}{ }^{2}$ & $\cdots$ & $b_{2}{ }^{m}$ & $\sum_{j=1}^{m} a_{j} b_{2}^{j}$ \\
$\vdots$ & $\cdots$ & $\cdots$ & $\cdots$ & $\cdots$ & $\sum^{m}{ }^{m} a_{j} b_{n}^{j}$ \\
$B_{n}$ & $b_{n}{ }^{1}$ & $b_{n}{ }^{2}$ & $\cdots$ & $b_{n}{ }^{m}$ & $\sum_{j=1}$ \\
& & & & & \\
\hline
\end{tabular}

\section{An empirical study on evaluation of regional logistics capability}

\subsection{Construction of the judgment matrix for consistency testing}

This paper selects six provinces or municipalities of Beijing, Shanghai, Henan, Guangdong, Yunnan and Heilongjiang which are representative of our country as regional logistics capacity evaluation samples $[5,6]$. 
The relative importance judgment matrix A-B of the target layer and the criterion layer is constructed.

Table 4.A-B judgment matrix.

\begin{tabular}{|c|c|c|c|c|c|c|}
\hline $\mathrm{A}$ & B1 & B2 & B3 & B4 & $\mathrm{Wi}$ & C.I. \\
\hline B1 & 1 & 2 & 3 & 2 & 0.41 & \multirow{4}{*}{$0.08<0.10$} \\
\hline B2 & 0.50 & 1 & 3 & 3 & 0.32 & \\
\hline B3 & 0.33 & 0.33 & 1 & 2 & 0.15 & \\
\hline B4 & 0.5 & 0.33 & 0.50 & 1 & 0.12 & \\
\hline
\end{tabular}

C.I. $=0.08$, the average randomness consistency index R.I. $=0.89$, the consistency ratio C.R. $=\frac{C . I .}{R . I .}=0.09 \leq$ 0.10 Through the consistency test. The relative importance judgment matrix-P of the criterion layer and the scheme layer is constructed, $B_{j}$-P,as shown in Table5 -8 .

Table 5. B1-C judgment matrix.

\begin{tabular}{|l|l|l|l|l|l|}
\hline B1 & C1 & C2 & C3 & Wi & C.I. \\
\hline C1 & 1 & 3 & 3 & 0.59 & \multirow{2}{*}{$0.05<0.10$} \\
C2 & 0.33 & 1 & 0.50 & 0.16 & \multirow{2}{*}{} \\
\cline { 1 - 4 } C3 & 0.33 & 2 & 1 & 0.25 & \\
\hline
\end{tabular}

Consistency test: C.I. $=0.08$, mean random consistency index R.I. $=0.52$, consistency ratio C.R. $=\frac{C . I .}{R . I .}=0.10 \leqq$ 0.10.Through the consistency test.

Table 6. B2 - Judgment Matrix.

\begin{tabular}{|l|l|l|l|l|}
\hline B2 & C4 & C5 & Wi & C.I. \\
\hline C4 & 1 & 0.50 & 0.33 & $0.00<0.10$ \\
\hline C5 & 2 & 1 & 0.67 & \\
\hline
\end{tabular}

Consistency test: C.I. $=0.00$, mean random consistency index R.I. $=0.52$, consistency ratio C.R. $=\frac{C . I .}{R . I .}=0.00 \leqq$ 0.10.Through the consistency test.

Table 7. B3- judgment matrix.

\begin{tabular}{|c|c|c|c|c|c|}
\hline B3 & C6 & $\mathrm{C} 7$ & $\mathrm{C} 8$ & $\mathrm{Wi}$ & C.I. \\
\hline C6 & 1 & 2 & 2 & 0.49 & \multirow{3}{*}{$0.05<0.10$} \\
\hline $\mathrm{C7}$ & 0.5 & 1 & 0.50 & 0.20 & \\
\hline $\mathrm{C} 8$ & 0.5 & 2 & 1 & 0.31 & \\
\hline
\end{tabular}

Consistency test: C.I. $=0.05$, mean random consistency index R.I. $=0.52$, consistency ratio C.R. $=\frac{C . I .}{R . I .}=0.10 \leqq$ 0.10.Through the consistency test.

Table 8.B4-Judgment Matrix.

\begin{tabular}{|c|c|c|c|c|c|}
\hline B4 & C9 & C11 & C12 & $\mathrm{Wi}$ & C.I. \\
\hline C9 & 1 & 3 & 2 & 0.26 & \multirow{4}{*}{$0.03<0.10$} \\
\hline C10 & 2 & 4 & 5 & 0.51 & \\
\hline C11 & 0.33 & 1 & 0.50 & 0.09 & \\
\hline C12 & 0.5 & 2 & 1 & 0.14 & \\
\hline
\end{tabular}

Consistency test: C.I. $=0.03$, mean random consistency index R.I. $=0.52$, consistency ratio C.R. $=\frac{C . I .}{R . I .}=0.03 \leqq$ 0.10.Through the consistency test. 


\subsection{Overall ranking}

According to the ranking of the three levels of the overall ranking index weight from large to small order: freight, logistics, the number of practitioners in the proportion of the tertiary industry, the number of logistics practitioners, postal and telecommunications business, logistics industry, investment in fixed assets, freight turnover, wholesale and retail Value of logistics at the end of the year, total output value of logistics industry, investment in fixed assets in the logistics industry as a proportion of total investment, logistics industry in GDP and logistics industry in total output value of tertiary industry.

Among all the 12 factors, the first one is the freight volume, the weight of 0.24 , is the primary factor affecting the regional logistics capacity. The second place is the number of logistics practitioners accounted for the proportion of tertiary industry practitioners, the weight of 0.21 . The third is the number of logistics practitioners, the weight of 0.11 . The fourth is the post and telecommunications business volume, its weight $0.10[7,8]$.

Table 9. Hierarchical total sort.

\begin{tabular}{|c|c|c|}
\hline $\begin{array}{l}\text { Secondary } \\
\text { indicators B }\end{array}$ & The third indicator $\mathrm{C}$ & $\begin{array}{c}\text { Total } \\
\text { weight }\end{array}$ \\
\hline \multirow[b]{3}{*}{ B1 } & Freight volume $\mathrm{C} 1$ & 0.24 \\
\hline & The rate of goods turnover $\mathrm{C} 2$ & 0.06 \\
\hline & Post and Telecommunications Services C3 & 0.10 \\
\hline \multirow[b]{2}{*}{ B2 } & Number of logistics employees $\mathrm{C} 4$ & 0.11 \\
\hline & The proportion of logistics industry in the tertiary industry $\mathrm{C} 5$ & 0.21 \\
\hline \multirow{3}{*}{ B3 } & Logistics industry fixed asset investment $\mathrm{C} 6$ & 0.08 \\
\hline & $\begin{array}{l}\text { Investment in Fixed Assets in the Logistics Industry as a Percent of Total } \\
\text { Investment C7 }\end{array}$ & 0.03 \\
\hline & End of the year Highway mileage C8 & 0.05 \\
\hline \multirow{4}{*}{ B4 } & Added value of logistics industry C9 & 0.03 \\
\hline & Added value of wholesale and retail trade $\mathrm{C} 10$ & 0.06 \\
\hline & $\begin{array}{l}\text { The added value of the logistics industry accounts for the proportion of tertiary } \\
\text { industry added value C } 11\end{array}$ & 0.01 \\
\hline & Value - added of Logistics Industry as a Percentage of GDP C12 & 0.02 \\
\hline
\end{tabular}

\subsubsection{Instance-related data The final result and sum of the data after the data are normalized and multiplied by the weigh}

The abbreviations in the table represent the cities respectively:

BJ:Beijing,SH:ShangHai,HN:HeNan,GD:GuangDong,YN:YunNan,HLJ:HeiLongJiang.

Table 10. The final result and the sum of each data multiplied by the weight.

\begin{tabular}{|c|c|c|c|l|l|l|}
\hline City & BJ & SH & HN & GD & YN & HLJ \\
\hline C1 & 0.06 & 0.05 & 0.13 & 0.24 & 0 & 0.03 \\
\hline C2 & 0.00 & 0.06 & 0.02 & 0.05 & 0 & 0.00 \\
\hline C3 & 0.00 & 0.02 & 0.02 & 0.10 & 0.02 & 0 \\
\hline C4 & 0.01 & 0.04 & 0 & 0.11 & 0.02 & 0.02 \\
\hline C5 & 0.12 & 0.21 & 0 & 0.04 & 0.16 & 0.18 \\
\hline C6 & 0.04 & 0 & 0.03 & 0.08 & 0.01 & 0.01 \\
\hline C7 & 0.01 & 0 & 0.01 & 0.03 & 0.00 & 0.00 \\
\hline
\end{tabular}




\begin{tabular}{|c|c|c|c|c|c|c|}
\hline C8 & 0.04 & 0 & 0.05 & 0.04 & 0.00 & 0.03 \\
\hline C9 & 0 & 0.01 & 0.02 & 0.03 & 0.01 & 0.00 \\
\hline C10 & 0 & 0.02 & 0.01 & 0.06 & 0.01 & 0.00 \\
\hline C11 & 0 & 0.00 & 0.01 & 0.00 & 0.00 & 0.00 \\
\hline C12 & 0 & 0.01 & 0.02 & 0.01 & 0.01 & 0.02 \\
\hline Sum & 0.29 & 0.43 & 0.33 & 0.80 & 0.25 & 0.30 \\
\hline
\end{tabular}

\section{Conclusion and prospect}

Based on AHP, this paper constructs the regional logistics capacity evaluation index data model, and draws the conclusion: in the six cities analyzed above, the regional logistics capacity The ranking order of the evaluation order is Guangdong, Shanghai, Henan, Heilongjiang, Beijing and Yunnan.

Coastal developed cities such as Shanghai and Guangdong should strengthen the publicity and construction of logistics standardization work, introduce advanced logistics infrastructure, optimize the allocation of resources, improve the management mode, enhance the competitiveness of enterprises from the system, and strive to reach the world leading level. How to make the developed city logistics management approach to adapt to the large data environment as soon as possible, and effective use of large data environment of unprecedented opportunities and challenges, is every science and technology workers inevitable and must be carefully considered.Inland areas such as Henan, Heilongjiang and other regions, regional logistics competitiveness in general, which is due to the less developed central and western regions, mainly relying on economic development, the second industry, logistics level is low, lack of regional logistics capacity. So to strengthen the region's logistics industry at all levels of reform efforts to change the mode of development and structure to tertiary industry development to drive the overall development. We should make use of the policies of central and western regions and other preferential policies to do the overall strategic planning of logistics, integrate the traditional "target-driven decision-making" and the "data-driven decision-making" concept and method in large data environment, and actively adapt to large data environment, Knowledge and perspective of the ability to form the core strengths of their respective regions in the fierce regional competition to occupy a favorable position.

\section{References}

1. Zhu Donghua,Wang Xuefeng,LiBing.Research on Management Method of Technological Innovation in Big Data Environment.Science of Science and Management of S. \& T.,2013(04):172-180.

2. $\mathrm{Xu}$ Zongben,Feng Zhiyan,Guo Xunhua.Big Data - Driven Management and Decision.Management of the world,2014(11):158-163.

3. Yang Shanlin,Zhou Kaile.Management Problems in Big Data - Based on Big Data.Journal of Management Sciences,2015(5):1-8.

4. Nie Xiaoping.An Economic Analysis of Regional Logistics.Regional Economy,2007(9):214-222.

5. China Statistical Yearbook. Beijing: China Statistics Press, 2015.

6. Guo Jinyu, Zhang Zhongbin, Qing Yun. Research and application of analytic hierarchy process. Chinese Journal of Safety Science, 2008,18 (5).

7. LI Yong, WANG Yun, XU Guang-yin.Study on Comprehensive Evaluation of Regional Logistics Planning Journal of Henan Agricultural University, 2009 (02)

8. LiuBao,Xu Shubo,Zhao Huanchen.Analytic Hierarchy Process-Planning Decision Tools.Systems Engineering,1984(06)23-30. 